\title{
D-penicillamine prevents ram sperm agglutination by reducing the disulphide bonds of a copper-binding sperm protein
}

\author{
T Leahy ${ }^{1}$, JP Rickard ${ }^{1}$, RJ Aitken ${ }^{2}$ and SP de Graaf ${ }^{1}$ \\ ${ }^{1}$ Faculty of Veterinary Science, The University of Sydney, Camperdown, New South Wales, Australia and \\ ${ }^{2}$ Discipline of Biological Sciences, Faculty of Science and IT and Faculty of Health and Medicine, \\ University of Newcastle, Callaghan, New South Wales, Australia
}

Correspondence should be addressed to T Leahy; Email: tamara.leahy@sydney.edu.au

\begin{abstract}
Head-to-head agglutination of ram spermatozoa is induced by dilution in the Tyrode's capacitation medium with albumin, lactate and pyruvate (TALP) and ameliorated by the addition of the thiol D-penicillamine (PEN). To better understand the association and disassociation of ram spermatozoa, we investigated the mechanism of action of PEN in perturbing sperm agglutination. PEN acts as a chelator of heavy metals, an antioxidant and a reducing agent. Chelation is not the main mechanism of action, as the broad-spectrum chelator ethylenediaminetetraacetic acid and the copper-specific chelator bathocuproinedisulfonic acid were inferior anti-agglutination agents compared with PEN. Oxidative stress is also an unlikely mechanism of sperm association, as PEN was significantly more effective in ameliorating agglutination than the antioxidants superoxide dismutase, ascorbic acid, $\alpha$-tocopherol and catalase. Only the reducing agents cysteine and DL-dithiothreitol displayed similar levels of non-agglutinated spermatozoa at $0 \mathrm{~h}$ compared with PEN but were less effective after $3 \mathrm{~h}$ of incubation $\left(37^{\circ} \mathrm{C}\right)$. The addition of $10 \mu \mathrm{M} \mathrm{Cu}{ }^{2+}$ to $250 \mu \mathrm{M}$ PEN $+\mathrm{TALP}$ caused a rapid reversion of the motile sperm population from a non-agglutinated state to an agglutinated state. Other heavy metals (cobalt, iron, manganese and zinc) did not provoke such a strong response. Together, these results indicate that PEN prevents sperm association by the reduction of disulphide bonds on a sperm membrane protein that binds copper. ADAM proteins are possible candidates, as targeted inhibition of the metalloproteinase domain significantly increased the percentage of motile, non-agglutinated spermatozoa $(52.0 \% \pm 7.8)$ compared with TALP alone $(10.6 \% \pm 6.1)$.

Reproduction (2016) 151 491-500
\end{abstract}

\section{Introduction}

We have previously shown that the extension of ram spermatozoa in the commonly used Tyrode's capacitation medium with albumin, lactate and pyruvate (TALP) causes rapid head-to-head sperm agglutination in a highly specific and persistent manner (Leahy et al. 2016). Ram sperm aggregation in TALP does not coincide with a loss of sperm function, as often seen after spermatozoa are exposed to physiochemical stressors such as high dilution or washing, cold shock, and extreme $\mathrm{pH}$ or osmotic conditions (Mann 1964). Agglutinated sperm retain their motility, and the phenomenon appears similar to the agglutination that occurs when sera (e.g. follicular fluid and plasma) are added to in vitro fertilisation (IVF) media to stimulate cholesterol efflux of ram spermatozoa (Ehrenwald et al. 1990, Funahashi \& Day 1993). It is uncertain whether this phenomenon is physiologically relevant or an artefact of in vitro sperm manipulation; however, agglutination of rabbit spermatozoa has been noted after placement in the doe uterine lumen (Brown \& Senger 1982).

Ram spermatozoa require serum for IVF (Huneau et al. 1994, Li et al. 2006), as TALP medium alone does not stimulate protein tyrosine phosphorylation and cholesterol efflux in this species (Colas et al. 2008, Leahy \& Gadella 2015, Leahy et al. 2016). Therefore, it is important to understand what factors are driving ram sperm association and disassociation, as it commonly occurs during ram sperm IVF. We have previously shown that the thiol D-penicillamine (PEN) is highly effective in preventing or reversing sperm association in TALP (Leahy et al. 2016). The effect of PEN was immediate, long-lasting and had no effect on total motility or the ability of spermatozoa to undergo capacitation. These characteristics make this compound well suited for in vitro use in spermhandling protocols to counteract agglutination issues. 
Penicillamine was named so because it is a degradation product of penicillin that contains an amine group (Fig. 1) (Abrahams et al. 1943). Penicillamine (PEN) also contains two other functional groups, a carboxyl and a sulphydryl (Fig. 1). Although it possesses no antibacterial properties, these functional groups impart a range of biochemical behaviours that have been therapeutically exploited for more than 50 years to treat copper toxicities (Walshe 1956). The sulphydryl group is of greatest biological significance, as it can combine with a multitude of compounds and act as a chelator or antioxidant as well as a participant in redox reactions as a reducing agent (Netter et al. 1987). In this study, we investigate how PEN perturbs sperm agglutination to shed some light on the factors involved in autologous sperm binding.

\section{Materials and methods}

\section{Chemicals}

Unless otherwise stated, products were sourced from SigmaAldrich and were of the highest reagent grade available. The base medium used was modified Tyrode's medium supplemented with albumin, lactate and pyruvate (TALP) (Parrish et al. 1988), which consisted of $2 \mathrm{mM} \mathrm{CaCl}, 3.1 \mathrm{mM} \mathrm{KCl}$, $0.4 \mathrm{mM} \mathrm{MgCl}, 95 \mathrm{mM} \mathrm{NaCl}, 0.3 \mathrm{mM} \mathrm{NaH} \mathrm{PO}_{4}, 10 \mathrm{mM}$ HEPES, $21.6 \mathrm{mM}$ Na lactate, $5 \mathrm{mM}$ glucose, $1 \mathrm{mM}$ Na pyruvate, $25 \mathrm{mM} \mathrm{NaHCO}, 0.03 \mathrm{mM}$ phenol red and $3 \mathrm{mg} / \mathrm{ml} \mathrm{BSA}$ (fatty acid free). The final $\mathrm{pH}$ and osmolarity of the various diluents was 7.4 and $300-310 \mathrm{mOsm} / \mathrm{L}$ respectively.

\section{Sperm preparation}

Ram semen was collected from two Merino rams and one Merino cross ram $(n=3)$ using an artificial vagina with project approval from the University of Sydney's Animal Ethics Committee (Protocol No: 2013/5854). Two ejaculates were collected from each ram, three times a week. Only ejaculates that had a wave motion score of 4 (out of 5 ) or higher were used. Spermatozoa were diluted to $50 \times 10^{6}$ spermatozoa $/ \mathrm{mL}$ in 1 $\mathrm{mL}$ aliquots and held for $3 \mathrm{~h}$ in an Eppendorf tube in a humidified incubator set at $38.5^{\circ} \mathrm{C}$ in an atmosphere of $5 \% \mathrm{CO}_{2}$.

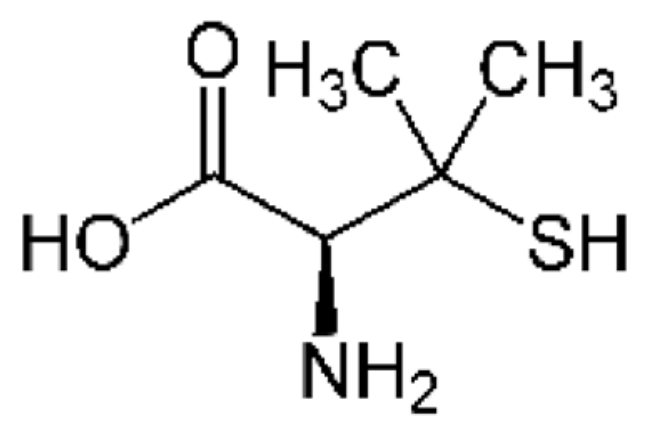

Figure 1 Structure of D-penicillamine.

\section{Experiment design}

Each experiment was replicated six times using two ejaculates from three Merino rams. Motility and agglutination were assessed immediately following sperm dilution ( $\mathrm{h}$ ) and after $3 \mathrm{~h}$ of incubation. Except in Experiment 7, all compounds of interest were added to TALP at the desired concentration and then the sperm samples were diluted to $50 \times 10^{6}$ spermatozoa $/ \mathrm{mL}$.

Experiment 1. As PEN is an effective copper chelator, the influence of copper ions $\left(\mathrm{Cu}^{2+}\right)$ on sperm agglutination in TALP was assessed. A dose course of copper sulphate $(0-500 \mu \mathrm{M})$ was added to TALP supplemented with $250 \mu \mathrm{M}$ PEN.

Experiment 2. Experiment 2 assessed the specificity of the effect of copper on inducing sperm agglutination by comparing it to a range of other heavy metals. A standard dose of $10 \mu \mathrm{M}$ of the following metals was added to TALP supplemented with $250 \mu \mathrm{M}$ PEN: iron sulphate heptahydrate, zinc sulphate heptahydrate, manganese sulphate monohydrate, cobalt sulphate heptahydrate and copper sulphate.

Experiment 3. A Cu ${ }^{2+}$-dependent lectin associated with agglutination of goat spermatozoa has been described (Roy et al. 2014). The lectin was sialic acid-specific and agglutinated cells could be dissociated with neutralised sialic acid (Roy et al. 2014). The aim of Experiment 3 was to assess the response of $0,1,10,20$ or $30 \mathrm{mM} \mathrm{N}$-acetylneuraminic acid (sialic acid; Cayman Chemicals) on TALP-induced ram sperm agglutination.

Penicillamine (PEN) can act as a chelator, an antioxidant and a reducing agent. Experiments $4-6$ were designed to compare the ability of PEN to reduce agglutination of ram spermatozoa in TALP with that of other chelators, antioxidants and reducing agents.

Experiment 4. Experiment 4 compared the effects of the broad-scale chelator, ethylenediaminetetraacetic acid disodium salt (EDTA) and the copper-specific chelator bathocuproinedisulfonic acid disodium salt (BCS) to PEN. To broaden the basis for comparisons between the effects of each substance studied, standardised low $(0.1 \mathrm{mM})$ and high $(1 \mathrm{mM})$ concentrations were tested.

Experiment 5. Experiment 5 compared the effects of four antioxidants to PEN (1 mM). L-ascorbic acid (VIT C; $1 \mathrm{mg} / \mathrm{mL}$ ) was supplemented at the physiological concentration in ram semen (Mann 1964). Superoxide dismutase (SOD; $800 \mathrm{IU}$ $\mathrm{mL}^{-1}$ ), catalase (150IU $\mathrm{mL}^{-1}$ ) and $\alpha$-tocopherol (VIT E; $1 \mathrm{mM}$; solubilised in ethanol with a final concentration of $0.5 \%(\mathrm{v} / \mathrm{v})$ ) were supplemented at levels that were previously shown to counteract sperm oxidative stress in vitro (Aitken \& Clarkson 1988, Maxwell \& Stojanov 1996, Leahy et al. 2010).

Experiment 6. Experiment 6 compared the reducing agents, reduced L-glutathione $(\mathrm{GSH})$, L-cysteine (CYS) and DL-dithiothreitol (DTT) to PEN. To broaden the basis for comparisons between the effects of each substance studied, standardised low $(0.1 \mathrm{mM})$ and high $(1 \mathrm{mM})$ concentrations were tested.

Experiment 7. ADAM (A disintegrin and metalloproteinase) proteins are involved in cell adhesion, are abundant on the extracellular sperm membrane (Loechel \& Wewer 2001, Byrne et al. 2012) and may be activated by copper (Loechel \& Wewer 2001). The aim of Experiment 7 was to assess the effect of targeting either the "integrin" or the "metalloproteinase" 
functions of ADAM proteins through the addition of a RGDS sequence blocking peptide $(0.1$ and $1 \mathrm{mM}$; In vitro technologies, Lane Cove West, NSW, Australia) or the ADAM metalloproteinase inhibitor tumour necrosis factor- $\alpha$ protease inhibitor-2 (TAPI-2, $25 \mu \mathrm{M}$; Sapphire Bioscience, Waterloo, NSW, Australia) respectively. The dose of TAPI-2 (Tousseyn et al. 2009) and RGDS peptide (Mould et al. 1991) utilised were based on the studies on somatic cells that showed physiological responses in these concentration ranges. Only in Experiment 7, samples were pre-incubated with various treatments at $500 \times 10^{6}$ spermatozoa $/ \mathrm{mL}$ for $15 \mathrm{~min}$ at $37^{\circ} \mathrm{C}$ in PBS and then diluted to $50 \times 10^{6}$ spermatozoa $/ \mathrm{mL}$ in TALP supplemented with the same treatments.

\section{Sperm auto-agglutination assay}

Spermatozoa were observed under light microscopy using phase-contrast optics (400 $\times$ magnification) with an Olympus BX51 microscope equipped with an Olympus DP73 digital camera. Four fields of view were recorded over $1 \mathrm{~min}$. Samples were randomised and coded, so the assessor was blind to sample treatment. The videos were watched frame by frame using the Olympus cellSens imaging software. Spermatozoa (200 cells counted per sample) were assigned to one of four categories: motile and non-agglutinated, motile and agglutinated, non-motile and non-agglutinated, or non-motile and agglutinated.

\section{Statistical analysis}

Statistical analysis was performed using linear mixed model regression in GENSTAT (version 16; VSN International, Hemel Hempstead, UK). Interactions between treatment effects and time were assessed with ejaculate and ram incorporated into the blocking structure. Data are presented as the modelderived mean \pm standard error of the mean (S.E.M.) of six replicates. Results are expressed as significant $(* P<0.05)$ and highly significant $(* * P<0.001)$ compared with control samples.

\section{Results}

\section{Low concentrations of cupric ions cause mass agglutination of motile spermatozoa}

TALP was supplemented with $250 \mu \mathrm{M}$ PEN to produce a non-agglutinated, control population (Fig. 2A \& Supplementary Video 1; control, representative sample at $0 \mathrm{~h}$ ). Supplementation of $10 \mu \mathrm{M}$ (Fig. 2B \& Supplementary Video 2; copper, representative sample at $0 \mathrm{~h}$ ) and $50 \mu \mathrm{M}$ $\mathrm{Cu}^{2+}$ ions had no effect on total motility but caused an immediate switch from a non-agglutinated motile state to an agglutinated motile state (Fig. 3). Copper-induced sperm agglutination occurred in a head-to-head manner in the area overlying the acrosome (Fig. 2B \& Supplementary Video 2, copper) and the association persisted throughout the 3-h test period. Copper was toxic from $100 \mu \mathrm{M}$ onwards and resulted in an increase in the percentage of non-agglutinated, non-motile spermatozoa
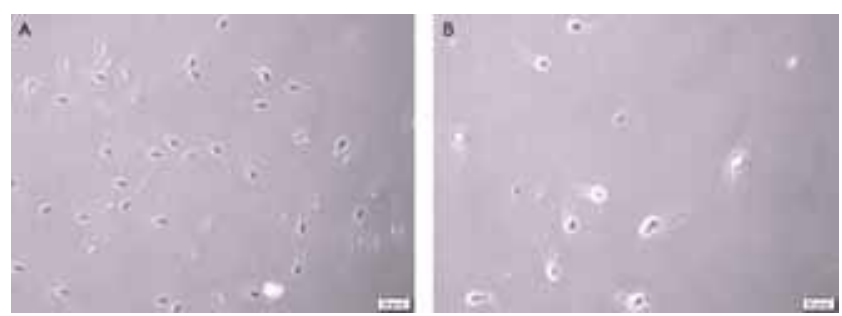

Figure $2 \mathrm{~A}$ representative image of ram spermatozoa in $\mathrm{TALP}+250 \mu \mathrm{M}$ PEN supplemented with (B) or without (A) $10 \mu \mathrm{M}$ $\mathrm{Cu}^{2+}$. Video files of these two sperm populations can be viewed in supplementary materials. Viewed under $400 \times$ magnification at $0 \mathrm{~h}$ of incubation.

at $100 \mu \mathrm{M}$ and an increase in both agglutinated and non-agglutinated, non-motile spermatozoa at $250 \mu \mathrm{M}$ (Fig. 3).

\section{Compared with other heavy metals, copper is a significantly stronger agglutination agent}

Copper caused significantly higher levels of sperm agglutination than the other heavy metals tested (Fig. 4). Copper-induced sperm agglutination was immediate, specific and broad scale. In the presence of copper, less than $1 \%$ of the sperm population were motile and non-agglutinated at both 0 and $3 \mathrm{~h}$ (Fig. 4). This effect was not evident in the other heavy metals tested. Zinc and manganese had no effect on sperm agglutination, and cobalt and iron only showed a moderate decrease in the percentage of non-agglutinated, motile spermatozoa at $3 \mathrm{~h}$. None of the heavy metals tested had an effect on total motility at the dose tested $(10 \mu \mathrm{M})$.

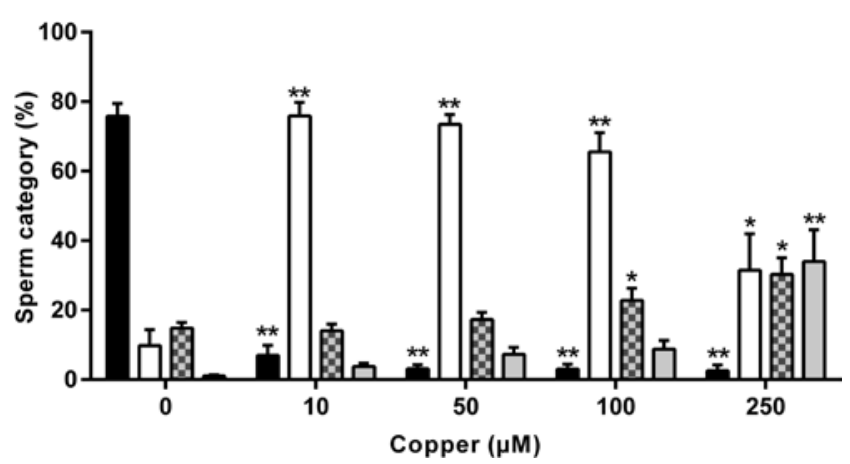

Figure 3 Dose response $(0-250 \mu \mathrm{M})$ of $\mathrm{Cu}^{2+}$ ions on ram sperm agglutination in TALP supplemented with $250 \mu \mathrm{M}$ PEN. Copper caused mass agglutination of motile spermatozoa (open bars) at the lowest dose tested $(10 \mu \mathrm{M})$, which was accompanied by a reduction in the percentage of non-agglutinated, motile spermatozoa (black bars). Toxic effects are evident from $100 \mu \mathrm{M}$ onwards with an increase in the percentage of non-agglutinated, non-motile spermatozoa (hatched bars) and an increase in non-motile, agglutinated spermatozoa (grey bars) at the highest dose tested. Data correspond to model derived mean \pm S.E.M. for six replicate samples assessed at 0 and $3 \mathrm{~h}$ and pooled over time. ${ }^{*} P<0.05$ and ${ }^{* *} P<0.001$ differences compared with control $(0 \mu \mathrm{M})$. 


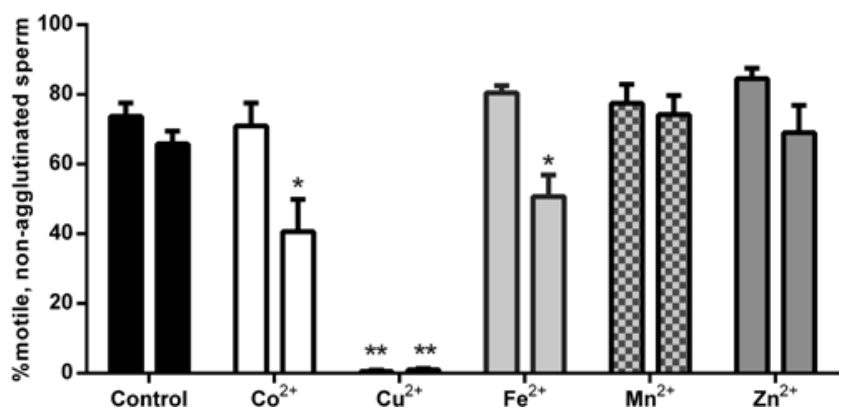

Figure 4 The influence of heavy metals on ram sperm agglutination. The effect of $10 \mu \mathrm{M}$ of the following metal ions was tested: cobalt $\left(\mathrm{Co}^{2+}\right)$, copper $\left(\mathrm{Cu}^{2+}\right)$, iron $\left(\mathrm{Fe}^{2+}\right)$, manganese $\left(\mathrm{Mn}^{2+}\right)$ and zinc $\left(\mathrm{Zn}^{2+}\right)$. Agglutination was assessed at 0 and $3 \mathrm{~h}$ and the data for both time points are shown (double columns within treatment). Data correspond to model derived mean \pm S.E.M. for six independent samples. ${ }^{*} P<0.05$ and ${ }^{* *} P<0.001$ different compared with corresponding hour of control sample $(\mathrm{TALP}+250 \mu \mathrm{M}$ PEN).

\section{Sialic acid has no effect on sperm agglutination}

The supplementation of neutralised sialic acid to TALP had no effect on sperm motility or agglutination. The percentage of motile, non-agglutinated spermatozoa supplemented with $0(3.2 \pm 1.1 \%), 1 \quad(3.0 \pm 1.3 \%)$, $10(3.5 \pm 0.9 \%), 20(3.8 \pm 0.9 \%)$ or $30(3.8 \pm 1.0 \%) \mathrm{mM}$ sialic acid was low and statistically similar. This suggests that the mechanism of sperm binding described herein does not involve a sialic acid-specific lectin as shown in goat spermatozoa (Roy et al. 2014).

\section{Chelation of extracellular free cupric or cuprous ions is unlikely to be the sole mechanism by which PEN prevents sperm association}

In comparison to the control (TALP only), both $1 \mathrm{mM}$ EDTA and $1 \mathrm{mM}$ BCS significantly increased the percentage of non-agglutinated, motile spermatozoa; however, this was only by a moderate amount compared with both 0.1 and $1 \mathrm{mM}$ PEN (Fig. 5A). This indicates that chelation is unlikely to be the sole mechanism by which PEN prevents sperm association.

\section{Protection from oxidative stress is unlikely to be the sole mechanism by which PEN prevents sperm association}

Catalase (CAT) and $\alpha$-tocopherol (VIT E) had no effect (Fig. 5B) on sperm agglutination compared with the control (TALP). L-ascorbic acid (VIT C; 3 h only) and superoxide dismutase (SOD; 0 and $3 \mathrm{~h}$ ) significantly increased the percentage of non-agglutinated, motile spermatozoa compared with the control, but only by a moderate amount in comparison to $1 \mathrm{mM}$ PEN (Fig. 5B). This indicates that protection from oxidative damage is unlikely to be the sole mechanism by which PEN prevents sperm association.
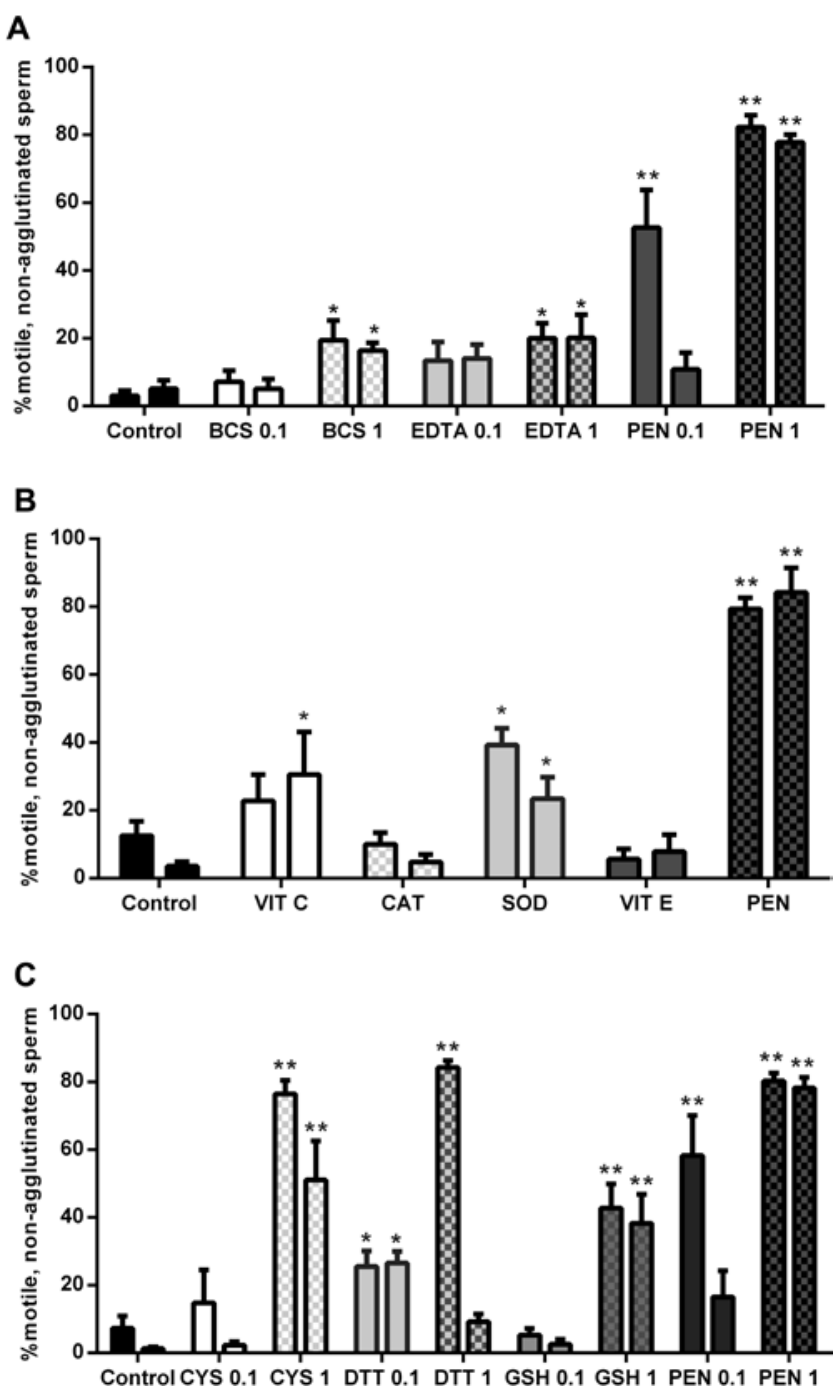

Figure 5 The influence of chelators, antioxidants and reductants on sperm agglutination in TALP. PEN has previously been shown to prevent or reverse agglutination of ram spermatozoa in TALP, but its mechanism of action is unknown. As D-penicillamine (PEN) can act as a chelator, an antioxidant or a reducing agent, the ability of PEN to prevent ram sperm agglutination in TALP was compared with these compounds. Agglutination was assessed at 0 and $3 \mathrm{~h}$ and data for both time points are shown (double columns within treatment). The control sample contains TALP medium alone. (A) shows the effects of the copper-specific chelator bathocuproinedisulfonic acid disodium salt (BCS; 0.1, $1 \mathrm{mM}$ ), the broad-scale chelator, ethylenediaminetetraacetic acid disodium salt (EDTA; 0.1 and $1 \mathrm{mM}$ ) and PEN (0.1, $1 \mathrm{mM}$ ). (B) shows the effects of five antioxidants: L-ascorbic acid (VIT C; $1 \mathrm{mg} / \mathrm{mL}$ ), catalase $(C A T ; 150 \mathrm{IU} / \mathrm{mL})$, superoxide dismutase $(\mathrm{SOD} ; 800 \mathrm{IU} / \mathrm{mL})$, DL- $\alpha$-tocopherol (VIT E; $1 \mathrm{mM}$ ) and $1 \mathrm{mM}$ PEN. (C) shows the effects of the reducing agents L-cysteine $(0.1,1 \mathrm{mM})$, DL-dithiothreitol (DTT; 0.1, $1 \mathrm{mM})$, reduced L-glutathione $(\mathrm{GSH} ; 0.1,1 \mathrm{mM})$ and PEN $(0.1,1 \mathrm{mM})$. Data correspond to model derived means \pm S.E.M. for six replicate samples. ${ }^{*} P<0.05$ and ${ }^{* *} P<0.001$ different compared with corresponding hour of control sample (TALP).

\section{The reducing action of PEN is the most likely mechanism by which PEN prevents sperm association}

The reductants showed the strongest anti-agglutination effect of all the compounds tested. Supplementation of 


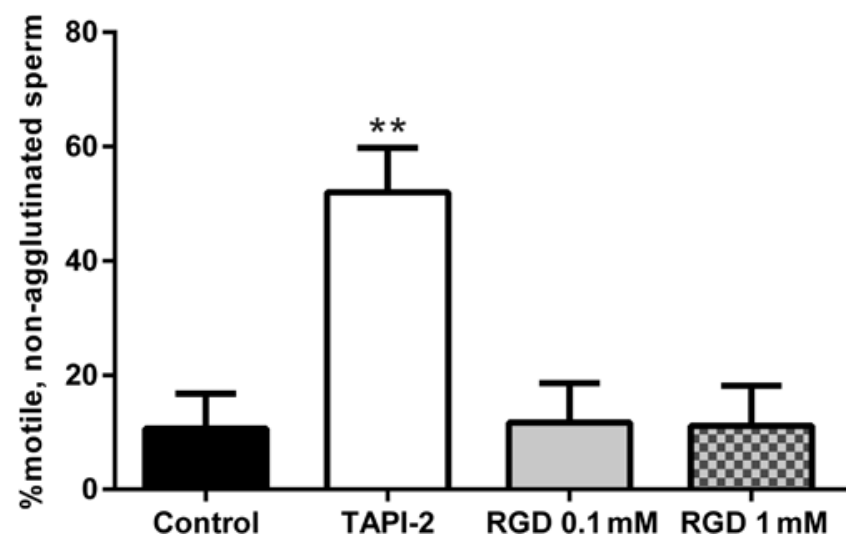

Figure 6 Effect of the ADAM metalloproteinase inhibitor tumour necrosis factor- $\alpha$ protease inhibitor-2 (TAPI-2, $25 \mu \mathrm{M})$ and the RGD sequence integrin blocking peptide $(0.1$ and $1 \mathrm{mM})$ on sperm agglutination in TALP. Data correspond to model derived mean \pm S.E.M. for six independent samples. Samples were assessed at 0 and $3 \mathrm{~h}$ and pooled across time period. ${ }^{*} P<0.05$ and ${ }^{* *} P<0.001$ differences compared with control.

$1 \mathrm{mM}$ cysteine (CYS) and DL-dithiothreitol (DTT) at $0 \mathrm{~h}$ caused a highly significant increase in the percentage of motile, non-agglutinated spermatozoa, which was equivalent to $1 \mathrm{mM}$ PEN (Fig. 5C). However, at the lower dose of $0.1 \mathrm{mM}$, the most effective reducing agent was still PEN.

Some of the reducing agents showed a striking dropoff in effectiveness from 0 to $3 \mathrm{~h}$. For example, freeswimming spermatozoa decreased by $72 \%$ from 0 to $3 \mathrm{~h}$ in $0.1 \mathrm{mM}$ PEN, whereas $1 \mathrm{mM}$ PEN did not change over time. It is important to note here that the large decrease in free-swimming spermatozoa seen in $1 \mathrm{mM}$ DDT at $3 \mathrm{~h}$ was not associated with an increase in agglutinated, motile spermatozoa, but a result of sperm toxicity evidenced by an increase in non-motile, non-agglutinated spermatozoa. With the exception of this DTT dose at this time point, no other compound decreased total sperm motility, and all other increases in non-agglutinated, motile spermatozoa were accompanied by decreases in agglutinated, motile spermatozoa.

\section{Inhibition of the metalloproteinase domain of ADAM proteins significantly increases the percentage of non- agglutinated, motile spermatozoa}

Targeted inhibition of the metalloproteinase domain with tumour necrosis factor- $\alpha$ protease inhibitor- 2 (TAPI2, $25 \mu \mathrm{M}$ ) significantly increased (Fig. 6) the percentage of motile, non-agglutinated spermatozoa compared with TALP alone (control). Pre-incubation with either 0.1 or $1 \mathrm{mM}$ RGD peptide to block RGD-binding sequences of the disintegrin domain of ADAM proteins had no effect on sperm agglutination (Fig. 6).

\section{Discussion}

In this study, we show that low concentrations of $\mathrm{Cu}^{2+}$ ions cause mass agglutination of ram spermatozoa
(Figs 2, 3, 4 and Supplementary Videos 1 and 2). In the presence of $10 \mu \mathrm{M} \mathrm{Cu}^{2+}$, more than $90 \%$ of the motile sperm population was agglutinated (Figs 3 and 4 ). Copper-mediated sperm agglutination was similar to TALP or sera-induced sperm agglutination (Senger \& Saacke 1976, Aalseth et al. 1978, Leahy et al. 2016) in that the association was immediate, persistent and occurred in an area overlying the acrosome and did not influence total motility. Plasma and follicular fluid contain relatively high levels of copper (14.16-18.25 $\mu \mathrm{M})$ ( $\mathrm{Ng}$ et al. 1987, Twomey et al. 2005, Picco et al. 2012). This may explain why the inclusion of sera in ovine in vitro fertilisation protocols causes similar agglutination to that induced by cupric ions and why PEN can also prevent sera-induced agglutination of ram sperm in IVF media (Leahy et al. 2016). It can be assumed that the agglutination of ram spermatozoa requires only trace amounts of copper as mass agglutination occurred when $10 \mu \mathrm{M}$ $\mathrm{Cu}^{2+}$ was supplemented to TALP containing a 25-fold higher dose of the copper chelator, PEN.

Ram spermatozoa have been previously noted to be highly reactive to copper. The motility of ram sper-

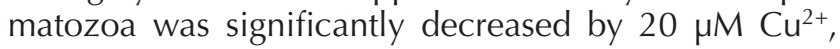
whereas a 100 -fold higher dose $(2 \mathrm{mM})$ was required to achieve a similar effect in both bull and human spermatozoa (White 1955). In this study, co-supplementation with $250 \mu \mathrm{M}$ PEN provided some protection from excess free copper ions as copper toxicity was not detected until the level of supplementation reached $100 \mu \mathrm{M} \mathrm{Cu}^{2+}$ (Fig. 3). Interestingly, the aforementioned study (White 1955) also reported that copper caused head-to-head agglutination of ram spermatozoa, and this effect was not noted in any of the other species tested.

The influence of copper on sperm agglutination was shown to be highly specific as supplementation with a range of other heavy metals did not cause mass agglutination (Fig. 3). It is intriguing that ram spermatozoa are so susceptible to exogenous copper because they have higher sperm-bound copper levels (estimated to be $18.9 \mu \mathrm{M}$ compared with $0.94-3.78 \mu \mathrm{M}$ for humans) and higher seminal plasma copper levels than a range of species including the bull, boar, stallion and human (Mann 1964, Massanyi et al. 2003).

A copper-dependent lectin that causes sperm agglutination has been observed on the outer membrane of mature caprine spermatozoa (Roy et al. 2014). This lectin was sialic acid specific, and agglutinated cells could be dissociated with neutralised sialic acid. In this study, supplementation of neutralised sialic acid to TALP had no effect on sperm motility or agglutination, suggesting that the mechanism of sperm binding described herein does not involve a sialic acid-specific lectin as shown in goat spermatozoa.

We have previously shown that the thiol D-penicillamine (PEN) is highly effective in preventing or reversing sperm association in TALP (Leahy et al. 2016). PEN can act as a reducing agent, chelator or antioxidant; 
however, it is unclear how PEN reduced agglutination. Cell aggregation has previously been linked to oxidative damage. Copper-induced lipid peroxidation has been implicated in platelet cell aggregation (Gorog \& Kovacs 1995, Neiva et al. 1997) and protein aggregation in Alzheimer's and prion disease (Moir et al. 1999, Viles 2012). Copper catalyses the generation of reactive oxygen species (ROS), which attacks polyunsaturated fatty acids (PUFAs) of the sperm membrane and causes lipid peroxidation, sperm membrane destabilisation and cell death (Aitken et al. 1989). PEN can chelate transition metals that catalyse lipid peroxidation (Aitken et al. 2012a,b) or directly neutralise ROS (Gupte \& Mumper 2007), limiting their ability to interfere with PUFAs of the sperm membrane. However, the range of antioxidants tested in this study showed no or minimal ability to prevent the agglutination of ram spermatozoa (Fig. 5B). L-ascorbic acid and superoxide dismutase (SOD) significantly increased the percentage of nonagglutinated, motile spermatozoa compared with the control but only by a moderate amount in comparison to PEN. Since L-ascorbic acid is a known reducing agent and SOD can chelate copper (Nordberg \& Arnér 2001, Ottaviano et al. 2008), it is possible that these secondary functions, as a reductant or chelator, contributed to this response (Fig. 5B). The variable results obtained with the antioxidants tested indicate that protection from oxidative stress is unlikely to be the sole mechanism by which PEN prevents sperm association.

As excess free copper ions cause agglutination, and the well-known copper chelator PEN prevents agglutination, it would follow that chelation of copper is a likely mechanism by which PEN prevents sperm association. However, other chelators, such as EDTA and BCS, that have a high affinity for copper were not highly effective in preventing sperm agglutination (Fig 5A). EDTA is a membrane-permeable chelator that binds $\mathrm{Cu}^{2+}$ with a high copper stability constant (18.8) due to its six chelate rings (Ding et al. 2011). BCS is an impermeable chelator with a copper stability constant of 6.1, which selectively chelates $\mathrm{Cu}^{+}$but will also bind $\mathrm{Cu}^{2+}$ (Patel et al. 1997). PEN has a similar copper stability constant (7.1) to BCS but is membrane permeable and can reduce $\mathrm{Cu}^{2+}$ to $\mathrm{Cu}^{+}$and bind to either of these copper forms (Smith et al. 1994, Ding et al. 2011). Interestingly, despite displaying higher or similar affinity for copper as PEN, both BCS and EDTA showed minimal effects on sperm agglutination. Multiple studies have shown that PEN has lower affinity for copper in vitro than a range of other common chelators (e.g. EDTA and cysteine) but significantly higher copper affinity in vivo (Tran-Ho et al. 1997, Ding et al. 2011). For this reason, PEN remains the chelator of choice for the treatment of patients with copper accumulation due to Wilson's disease or other heavy metal intoxication (Walshe 2011). The superiority of PEN over EDTA in vivo implies that copper chelation therapy is unlikely to depend on complexation alone (Tran-Ho et al. 1997). The reasons why PEN is superior to EDTA for in vivo copper chelation therapy have been the focus of immense interest and are proposed to rely on two factors (1) that PEN can liberate $\mathrm{Cu}^{2+}$ from metalloproteins by reduction to $\mathrm{Cu}^{+}$(May \& Williams 1977) and (2) that PEN can form stable complexes with multiple ligands $\left(\mathrm{Cu}^{2+}, \mathrm{Cu}^{+}\right.$and other thiols $)$and produce a stable anionic multivalent copper cluster $\left(\mathrm{Cu}_{6}^{2+} \mathrm{Cu}_{8}^{+} \mathrm{PEN}_{12} \mathrm{Cl}\right)^{5-}($ Birker \& Freeman 1977, Kato et al. 1999). EDTA can prevent copper-dependent biological events when it is added to media containing free copper but cannot despoil copper from previously formed copper - protein complexes (Jimenez \& Speisky 2000). Therefore, it is likely that it is not free $\mathrm{Cu}^{2+}$ or $\mathrm{Cu}^{+}$ions in the TALP medium that caused sperm agglutination, as the chelators EDTA or BCS were added to the diluent before sperm extension. Rather it is copper that is bound to sperm proteins that is being modified by the extension of spermatozoa in TALP, as EDTA would not be able to chelate copper in this form (Jimenez \& Speisky 2000).

Of all the compounds tested, only the thiols (proteins with a sulphydryl bond), which act as reducing agents, showed strong anti-agglutination effects (Fig. 5C). This suggests that the mechanism of action of PEN is conferred by its ability to donate an electron to another molecule and act as a reductant in redox reactions (Fig. 7). Cysteine and DTT $(1 \mathrm{mM})$ displayed similar levels of non-agglutinated spermatozoa at 0 h compared with $1 \mathrm{mM}$ PEN but were less effective after $3 \mathrm{~h}$. At the lower dose of $0.1 \mathrm{mM}$, PEN was also the most effective reducing agent. The analysis of the mechanisms underlying the oxidation of thiols explains why PEN may be more effective in initiating sperm disassociation and maintaining spermatozoa in a disassociated state. PEN has been proposed to undergo a higher rate of oxidation under physiological conditions (e.g. $\mathrm{pH}$ 7) compared with other thiols (e.g. cysteine 8.3 and glutathione 8.8 ) because the pKa of its $\mathrm{SH}$ functional groups (7.9) is lower (Netter et al. 1987), making it more effective at lower doses. How PEN maintains the sperm population in a non-agglutinated form by keeping the copper complex in a reduced state is more complex. Smith et al. (1994) outlined the following reaction sequence for the oxidation of thiols by copper. Cupric ions react with RSH (where R denotes the $\mathrm{R}$ group of the thiol and $\mathrm{SH}$ denotes the sulphydryl bond of the thiol) to form a $\mathrm{Cu}^{2+}-\mathrm{RSH}$ complex in which $\mathrm{Cu}^{2+}$ is reduced to $\mathrm{Cu}^{+}$and $\mathrm{RSH}$ is oxidised (RS•) (Reaction 1). Two of the radicals (RS•) react to form a disulphide (Reaction 2) and $\mathrm{Cu}^{+}$reacts with a second thiol to form a Cu${ }^{+}$thiol complex (Reaction 3 ). The ratelimiting step of the process is considered (Smith et al. 1994) to rely on the reoxidation of the RSCu+ complex (Reaction 4), as it results in the release of $\mathrm{Cu}^{2+}$ where itcan participate in further redox cycling (Reaction 1). 


\section{NOT ABLE TO AGGLUTINATE}

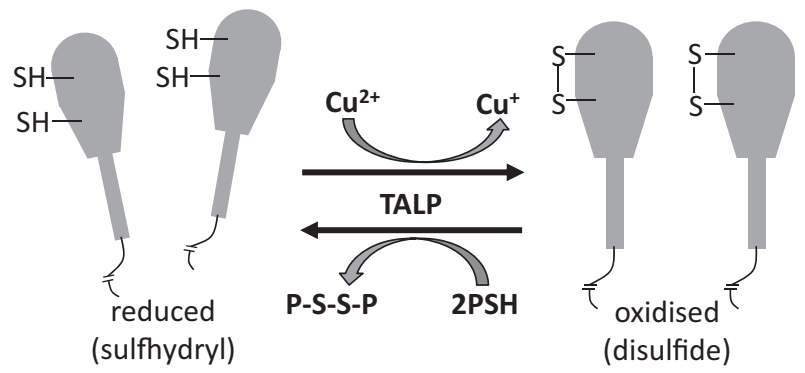

Figure 7 Proposed model of ram sperm agglutination. The data presented in this article suggest a model by which PEN (denoted as PSH to show sulphydryl bond) prevents or reverts sperm association by reducing the disulphide bonds $(\mathrm{S}-\mathrm{S})$ of a sperm protein to free sulphydryls $(\mathrm{SH})$. Copper $\left(\mathrm{Cu}^{2+}\right)$ causes the opposite effect by oxidising free sulphydryl bonds to disulphide bonds.

Reaction 1: $2 \mathrm{Cu}^{2+}+2 \mathrm{RSH} \rightarrow 2 \mathrm{Cu}^{2+} \mathrm{RS}+2 \mathrm{H}^{+} \rightarrow 2 \mathrm{Cu}^{+}+2 \mathrm{RS}+2 \mathrm{H}^{+}$

Reaction 2: 2RS $\rightarrow$ RSSR

Reaction 3: $2 \mathrm{Cu}^{+}+\mathrm{RSH} \rightarrow 2 \mathrm{RSCu}^{+}$

Reaction 4: $2 \mathrm{RSCu}^{+}+2 \mathrm{O}_{2} \rightarrow 2 \mathrm{Cu}^{2+}+2 \mathrm{O}_{2}$

The rate of reoxidation of the RSCu+ complex is dependent on the R-group of the thiol (Smith et al. 1994). Reoxidation of $\mathrm{Cu}^{+}$(Reaction 4) in a PEN complex is considered to occur at a slower rate, compared with other thiols, as the $\mathrm{Cu}^{+}$is partially protected from further oxidative attack by steric shielding from the two methyl groups $\left(\mathrm{CH}_{3}\right.$; Fig. 1$)$ of the PEN side chain (Birker \& Freeman 1977).

If sperm disassociation is occurring due to the reduction of copper bound to a sperm protein, or the reduction of a disulphide bond to free sulphydryl groups in a sperm protein, then the re-association of spermatozoa is due to the re-oxidation of these proteins over time in the highly oxidising extracellular environment. Such a response is clearly evident when PEN is provided at a rate-limiting dose $(0.1 \mathrm{mM})$ but not when excess PEN is present at the higher dose of $1 \mathrm{mM}$ (Fig. 5). Reversible thiol-disulphide redox reactions are a functional switch for various important fertilisation-related signalling events. The oxidation of thiols to form disulphide bridges and the reduction of disulphide bridges to free sulphydryls on the sperm surface have been shown to regulate capacitation-related sperm proteins ( $\mathrm{O}^{\prime}$ Flaherty 2015). PEN and other thiols have also been shown to initiate sperm release through the reduction of sperm surface disulphides to sulphydryls (Talevi et al. 2007, Gualtieri et al. 2009).

A disintegrin and metalloproteinase (ADAM) proteins are good candidates for involvement in autologous sperm agglutination because they bind metals, are involved in cell adhesion (Seals \& Courtneidge 2003, White 2003, Weber \& Saftig 2012), contain a cysteine-rich domain and are abundant on the extracellular surface of the sperm membrane (Byrne et al. 2012). In this study, targeted inhibition of the ADAM metalloprotease domain significantly increased (Fig. 6) the percentage of motile, non-agglutinated spermatozoa $(52.0 \% \pm 7.8)$ compared with TALP $(10.6 \% \pm 6.1)$, suggesting that this domain may be involved in autologous sperm binding.

ADAMs are zinc-binding proteins; however, there are known examples that are activated by copper as metal binding sites of proteins are likely sites for oxygen-based reactions (Wilcox et al. 2001). For example, copper oxidises the zinc binding Cys residue of the HIV retrovirus nucelocapsid p7 protein (Yu et al. 1995). Oxidation of the Cys thiolate ligand does not affect binding of the zinc to the metalloprotease domain but results in three specific disulphide bonds among the six cysteines (Yu et al. 1995). Copper oxidation of one of the amino acid residues in the zinc binding site has also been shown to change the conformation of ADAM12-s to its mature, active form (Loechel \& Wewer 2001). The ADAM metalloprotease domain participates in ectodomain shedding of multiple substrates including amyloid precursor protein, prion protein, heparin binding epidermal growth factor, tumour necrosis factor, L-selectin and various interleukins (Seals \& Courtneidge 2003, White 2003, Weber \& Saftig 2012). ADAMs cleave and remodel extracellular matrix proteins through the proteolytic release of these signalling factors (White 2003). Interestingly, many of these substrates have been shown to interact with copper (Hesse et al. 1994, Moir et al. 1999, Viles 2012, McDonald et al. 2014), and physiological concentrations of copper have been shown to stimulate zinc metalloproteinase ectodomain shedding of cell surface proteins. For example, copper-induced zinc metalloproteinase shedding of two key signalling and adhesion proteins, Jagged 1 and E-cadherin, was shown to be post-translationally modulated and enhanced the invasion of a PC3 cancer cell line (ParrSturgess et al. 2012).

However, targeting of the integrin domain by pre-incubation with either 0.1 or $1 \mathrm{mM}$ of the RGD blocking peptide had no effect on sperm agglutination (Fig. 6). Although this suggests that sperm agglutination is not dependent on RGD, it does not rule out ADAM-mediated cell adhesion. Only a subset of ADAM proteins, such as ADAM15, display the integrin binding motif Arg-Gly-Asp (RGD) in their disintegrin domain with the majority displaying an XCD (where $X$ is an amino acid) sequence (Lu et al. 2010). Cell adhesion is also not restricted to the disintegrin domain of ADAM proteins. The cysteine-rich domain of ADAM proteins can bind directly to cell surface syndecans (ADAM12) (Iba et al. 2000) and the Von Willebrand factor (ADAM13) (de Groot et al. 2015). The mechanism by which ADAM proteins may mediate autologous sperm binding remains far from 
certain. Ongoing investigation on the influence of ADAM proteins in other fertilisation-related events, such as sperm-zona pellucida binding, will shed further light on the role of these multifunctional proteins in cell association and signalling within the reproductive tract (Dun et al. 2012, Okabe 2015).

\section{Conclusion}

In this study, we show that trace levels of copper ions cause mass agglutination of ram spermatozoa in a manner similar to that of TALP-induced sperm agglutination. The effect is highly specific as a similar response was not provoked by other heavy metals. The nucleophilic thiol, penicillamine, can act as an antioxidant, a reducing agent or a chelator and has previously been shown to prevent or reverse ram sperm agglutination. Comparison of PEN to compounds in these classes showed that only the reducing agents (particularly cysteine and DTT) displayed similar levels of non-agglutinated spermatozoa as PEN. This suggests that the mechanism of action of PEN is conferred by its ability to donate an electron to another molecule and act as a reductant in redox reactions. Together, these results indicate that PEN prevents sperm association by the reduction of disulphide bonds of a sperm membrane protein that binds copper. ADAM proteins are possible candidates, as targeted inhibition of the metalloproteinase domain of these proteins reduces agglutination; however, further research is required to elucidate how ADAM proteins mediate ram sperm agglutination.

\section{Declaration of interest}

The authors declare that there is no conflict of interest that could be perceived as prejudicing the impartiality of the research reported.

\section{Funding}

This work was supported by funding from the NSW Stud Merino Breeders Association Trust and Australian Wool Innovation Limited.

\section{Acknowledgements}

The authors are grateful for the technical assistance of K. Heasman.

\section{References}

Aalseth EP, Senger PL \& Becker WC 1978 The relationship of sperm viability and concentration to serum-induced head-to-head agglutination of bovine spermatozoa. Journal of Reproduction and Fertility $\mathbf{5 3}$ 193-196. (doi:10.1530/jrf.0.0530193)
Abrahams EP, Chain E, Baker W \& Robinson R 1943 Penicillamine, a characteristic degradation product of penicillin. Nature 151107.

Aitken RJ \& Clarkson JS 1988 Significance of reactive oxygen species and antioxidants in defining the efficacy of sperm preparation techniques. Journal of Andrology 9 367-376.

Aitken RJ, Clarkson JS \& Fishel S 1989 Generation of reactive oxygen species, lipid peroxidation, and human sperm function. Biology of Reproduction 41 183-197.

Aitken RJ, Gibb Z, Mitchell LA, Lambourne SR, Connaughton HS \& De Iuliis GN 2012a Sperm motility is lost in vitro as a consequence of mitochondrial free radical production and the generation of electrophilic aldehydes but can be significantly rescued by the presence of nucleophilic thiols. Biology of Reproduction 87 110. (doi:10.1095/ biolreprod.112.102020)

Aitken RJ, Whiting S, De luliis GN, McClymont S, Mitchell LA \& Baker MA 2012 b Electrophilic aldehydes generated by sperm metabolism activate mitochondrial reactive oxygen species generation and apoptosis by targeting succinate dehydrogenase. Journal of Biological Chemistry 287 33048-33060. (doi:10.1074/jbc.M112.366690)

Birker P \& Freeman HC 1977 Structure, properties, and function of a copper(i)-copper(ii) complex of D-penicillamine - pentathallium(i) mu-8chloro-dodeca(d-penicillaminato)-octacuprate(i)hexacuprate(ii) normalhydrate. Journal of the American Chemical Society 99 6890-6899. (doi:10.1021/ja00463a019)

Brown DV \& Senger PL 1982 Influence of incubation in utero on motility and head-to-head agglutination of ejaculated rabbit spermatozoa. Journal of Reproduction and Fertility 66 283-289. (doi:10.18632/ oncotarget)

Byrne K, Leahy T, McCulloch R, Colgrave ML \& Holland MK 2012 Comprehensive mapping of the bull sperm surface proteome. Proteomics 12 3559-3579. (doi:10.1002/pmic.201200133)

Colas C, James P, Howes L, Jones R, Cebrian-Perez JA \& Muino-Blanco T 2008 Cyclic-AMP initiates protein tyrosine phosphorylation independent of cholesterol efflux during ram sperm capacitation. Reproduction Fertility and Development 20 649-658. (doi:10.1071/RD08023)

de Groot R, Lane DA \& Crawley JT 2015 The role of the ADAMTS13 cysteine-rich domain in VWF binding and proteolysis. Blood 125 1968-1975. (doi:10.1182/blood-2014-08-594556)

Ding X, Xie H \& Kang YJ 2011 The significance of copper chelators in clinical and experimental application. Journal of Nutritional Biochemistry 22 301-310.

Dun MD, Anderson AL, Bromfield EG, Asquith KL, Emmett B, McLaughlin EA, Aitken RJ \& Nixon B 2012 Investigation of the expression and functional significance of the novel mouse sperm protein, a disintegrin and metalloprotease with thrombospondin type 1 motifs number 10 (ADAMTS10). International Journal of Andrology 35 572-589. (doi:10.1111/ija.2012.35.issue-4)

Ehrenwald E, Foote RH \& Parks JE 1990 Bovine oviductal fluid components and their potential role in sperm cholesterol efflux. Molecular Reproduction and Development 25 195-204. (doi:10.1002/(ISSN) 1098-2795)

Funahashi H \& Day BN 1993 Effects of follicular fluid at fertilization in vitro on sperm penetration in pig oocytes. Journal of Reproduction and Fertility 99 97-103.

Gorog P \& Kovacs IB 1995 Lipid peroxidation by activated platelets: a possible link between thrombosis and atherogenesis. Atherosclerosis 115 121-128. (doi:10.1016/S0003-4975(98)01354-X)

Gualtieri R, Mollo V, Duma G \& Talevi R 2009 Redox control of surface protein sulphhydryls in bovine spermatozoa reversibly modulates sperm adhesion to the oviductal epithelium and capacitation. Reproduction 138 33-43. (doi:10.1530/REP-08-0514)

Gupte A \& Mumper RJ 2007 An investigation into copper catalyzed D-penicillamine oxidation and subsequent hydrogen peroxide generation. Journal of Inorganic Biochemistry 101 594-602.

Hesse L, Beher D, Masters CL \& Multhaup G 1994 The $\beta A 4$ amyloid precursor protein binding to copper. FEBS Letters 349 109-116. (doi:10.1016/S0006-2952(97)00062-2)

Huneau D, Crozet N \& Ahmed-Ali M 1994 Estrous sheep serum as a potent agent for ovine IVF: effect on cholesterol efflux from spermatozoa and the acrosome reaction. Theriogenology 42 1017-1028. (doi:10.1002/ (ISSN)1098-2795) 
Iba K, Albrechtsen R, Gilpin B, Fröhlich C, Loechel F, Zolkiewska A Ishiguro K, Kojima T, Liu W \& Langford JK 2000 The cysteine-rich domain of human ADAM 12 supports cell adhesion through syndecans and triggers signaling events that lead to $\beta 1$ integrin-dependent cell spreading. Journal of Cell Biology 149 1143-1156. (doi:10.1083/ jcb.149.5.1143)

Jimenez I \& Speisky H 2000 Effects of copper ions on the free radicalscavenging properties of reduced gluthathione: implications of a complex formation. Journal of Trace Elements in Medicine and Biology 14 161-167.

Kato N, Nakamura M \& Uchiyama T 1999 1H NMR studies of the reactions of copper(I) and copper(II) with D-penicillamine and glutathione. Journal of Inorganic Biochemistry 75 117-121.

Leahy T, Celi P, Bathgate R, Evans G, Maxwell WMC \& Marti JI 2010 Flow-sorted ram spermatozoa are highly susceptible to hydrogen peroxide damage but are protected by seminal plasma and catalase. Reproduction Fertility and Development 22 1131-1140. (doi:10.1071/ RD09286)

Leahy T \& Gadella BM 2015 New insights into the regulation of cholesterol efflux from the sperm membrane. Asian Journal of Andrology 17 561-567.

Leahy T, Rickard JP, Aitken RJ \& de Graaf SP 2016 Penicillamine prevents ram sperm agglutination in media that support capacitation. Reproduction 151 167-177.

Li F, Pi WH, Zhu HZ, Zhang SS, Liu SR \& Xue JL 2006 The effect of estrous ewe serum and heparin on in vitro fertilization and subsequent embryonic development in sheep. Small Ruminant Research $\mathbf{6 3}$ 226-232.

Loechel F \& Wewer UM 2001 Activation of ADAM 12 protease by copper. FEBS Letters 506 65-68. (doi:10.1016/j.bmcl.2014.09.077)

Lu D Scully D, Kakkar V \& Lu X 2010 ADAM-15 disintegrin-like domain structure and function. Toxins 2 2411-2427. (doi:10.3390/ toxins2102411)

Mann T 1964 The Biochemistry of Semen and of the Male Reproductive Tract. London, UK: Methuen and Co Ltd.

Massanyi P, Trandzik J, Nad P, Toman R, Skalicka M \& Korenekova B 2003 Seminal concentrations of trace elements in various animals and their correlations. Asian Journal of Andrology 5 101-104. (doi:10.1111/ jva.2007.54.issue-6)

Maxwell WMC \& Stojanov T 1996 Liquid storage of ram semen in the absence or presence of some antioxidants. Reproduction, Fertility and Development 8 1013-1020.

May PM \& Williams DR 1977 Computer simulation of chelation therapy plasma mobilizing index as a replacement for effective stability constant. FEBS Letters 78 134-138. (doi:10.1039/C5DT02129D)

McDonald AJ, Dibble JP, Evans EG \& Millhauser GL 2014 A new paradigm for enzymatic control of alpha-cleavage and beta-cleavage of the prion protein. Journal of Biological Chemistry 289 803-813. (doi:10.1074/jbc. M113.502351)

Moir RD Atwood CS, Romano DM, Laurans MH, Huang X, Bush AI, Smith JD \& Tanzi RE 1999 Differential effects of apolipoprotein E isoforms on metal-induced aggregation of $A \beta$ using physiological concentrations. Biochemistry 38 4595-4603. (doi:10.1021/ bi982437d)

Mould AP, Komoriya A, Yamada KM \& Humphries MJ 1991 The CS5 peptide is a second site in the IIICS region of fibronectin recognized by the integrin alpha 4 beta 1 . Inhibition of alpha 4 beta 1 function by RGD peptide homologues. Journal of Biological Chemistry 266 3579-3585.

Neiva TJ, Fries DM, Monteiro HP, D'Amico EA \& Chamone DA 1997 Aluminum induces lipid peroxidation and aggregation of human blood platelets. Brazilian Journal of Medical and Biological Research 30 599-604.

Netter P, Bannwarth B, Pere P \& Nicolas A 1987 Clinical pharmacokinetics of D-penicillamine. Clinical Pharmacokinetics 13 317-333. (doi:10.1111/bcp.1992.34.issue-1)

Ng SC, Karunanithy R, Edirisinghe WR, Roy AC, Wong PC \& Ratnam SS 1987 Human follicular fluid levels of calcium, copper and zinc. Gynecologic and Obstetric Investigation 23 129-132. (doi:10.1159/000298848)
Nordberg J \& Arnér ESJ 2001 Reactive oxygen species, antioxidants, and the mammalian thioredoxin system. Free Radical Biology and Medicine 31 1287-1312. (doi:10.1186/s12885-015-1383-x)

O'Flaherty C 2015 Redox regulation of mammalian sperm capacitation. Asian Journal of Andrology 17 583-590. (doi:10.4103/1008682X.153303)

Okabe M 2015 Mechanisms of fertilization elucidated by genemanipulated animals. Asian Journal of Andrology 17 646-652. (doi:10.4103/1008-682X.153299)

Ottaviano FG, Handy DE \& Loscalzo J 2008 Redox Regulation in the extracellular environment. Circulation Journal 72 1-16. (doi:10.1007/ s11010-009-0049-x)

Parr-Sturgess CA Tinker CL, Hart CA, Brown MD, Clarke NW \& Parkin ET 2012 Copper modulates zinc metalloproteinase-dependent ectodomain shedding of key signaling and adhesion proteins and promotes the invasion of prostate cancer epithelial cells. Molecular Cancer Research 10 1282-1293. (doi:10.1158/1541-7786.MCR-12-0312)

Parrish JJ, Suskoparrish J, Winer MA \& First NL 1988 Capacitation of bovine spermatozoa by heparin. Biology of Reproduction $\mathbf{3 8}$ 1171-1180. (doi:10.1095/biolreprod38.5.1171)

Patel R, Svistunenko D, Wilson M \& Darley-Usmar V 1997 Reduction of $\mathrm{Cu}$ (II) by lipid hydroperoxides: implications for the copper-dependent oxidation of low-density lipoprotein. Biochemical Journal 322 425-433. (doi:10.1074/jbc.273.48.31731)

Picco SJ, Rosa DE, Anchordoquy JP, Anchordoquy JM, Seoane A, Mattioli GA \& Furnus CC 2012 Effects of copper sulphate concentrations during in vitro maturation of bovine oocytes. Theriogenology 77 373-381. (doi:10.1016/j.theriogenology.2011.08.009)

Roy D, Dey S, Majumder GC \& Bhattacharyya D 2014 Occurrence of novel $\mathrm{Cu}(2+)$-dependent sialic acid-specific lectin, on the outer surface of mature caprine spermatozoa. Glycoconjugate Journal 31 281-288. (doi:10.1016/j.ijbiomac.2015.12.021)

Seals DF \& Courtneidge SA 2003 The ADAMs family of metalloproteases: multidomain proteins with multiple functions. Genes \& Development 17 7-30. (doi:10.1186/1476-4598-14-6)

Senger PL \& Saacke RG 1976 Serum-induced head-to-head agglutination of bovine spermatozoa. Journal of Reproduction and Fertility 47 215-219. (doi:10.1111/rda.2012.47.issue-s4)

Smith RC, Reed VD \& Hill WE 1994 Oxidation of thiols by copper(II). Phosphorus, Sulfur, and Silicon and the Related Elements 90 147-154. (doi:10.1016/0162-0134(93)80038-B)

Talevi R, Zagami M, Castaldo M \& Gualtieri R 2007 Redox regulation of sperm surface thiols modulates adhesion to the fallopian tube epithelium. Biology of Reproduction 76 728-735. (doi:10.1095 /biolreprod.106.056028)

Tousseyn T, Thathiah A, Jorissen E, Raemaekers T, Konietzko U, Reiss K, Maes E, Snellinx A, Serneels L, Nyabi O et al. 2009 ADAM10, the ratelimiting protease of regulated intramembrane proteolysis of notch and other proteins, is processed by ADAMS-9, ADAMS-15, and the?-secretase. Journal of Biological Chemistry 284 11738-11747.

Tran-Ho LC, May PM \& Hefter GT 1997 Complexation of copper(I) by thioamino acids. Implications for copper speciation in blood plasma. Journal of Inorganic Biochemistry 68 225-231. (doi:10.1016/S01620134(97)00097-4)

Twomey PJ, Viljoen A, House IM, Reynolds TM \& Wierzbicki AS 2005 Relationship between serum copper, ceruloplasmin, and non-ceruloplasmin-bound copper in routine clinical practice. Clinical Chemistry 51 1558-1559. (doi:10.1016/j.clinbiochem.2007. 04.002)

Viles JH 2012 Metal ions and amyloid fiber formation in neurodegenerative diseases. Copper, zinc and iron in Alzheimer's, Parkinson's and prion diseases. Coordination Chemistry Reviews 256 2271-2284.

Walshe JM 1956 Penicillamine, a new oral therapy for Wilson's disease. American Journal of Medicine 21 487-495. (doi:10.1016/00029343(56)90066-3)

Walshe JM 2011 Penicillamine neurotoxicity: an hypothesis. ISRN Neurology 2011 4. (doi:10.5402/2011/464572)

Weber S \& Saftig P 2012 Ectodomain shedding and ADAMs in development. Development 139 3693-3709. 
White IG 1955 The toxicity of heavy metals to mammalian spermatozoa. Australian Journal of Experimental Biology and Medical Science 33 359-366. (doi:10.1038/icb.1955.36)

White JM 2003 ADAMs: modulators of cell-cell and cell-matrix interactions. Current Opinion in Cell Biology 15 598-606. (doi:10.1016/j. ceb.2003.08.001)

Wilcox DE, Schenk AD, Feldman BM \& Xu Y 2001 Oxidation of Zinc-binding cysteine residues in transcription factor proteins. Antioxidants \& Redox Signaling 3 549-564. (doi:10.1089/1523086 0152542925)

Yu X, Hathout Y, Fenselau C, Sowder RC, Henderson LE, Rice WG, Mendeleyev J \& Kun E 1995 Specific disulfide formation in the oxidation of HIV-1 zinc finger protein nucleocapsid p7. Chemical Research in Toxicology 8 586-590. (doi:10.1021/ tx00046a013)

Received 24 December 2015

First decision 11 January 2015

Revised manuscript received 21 January 2016

Accepted 8 February 2016 